\title{
LEGO® -Based Clinical Intervention with LEGOßSERIOUS PLAY® and Six Bricks for Emotional Regulation and Cognitional Reconstruction
}

\author{
Pay-Ling Harn* \\ Applied psychology Department, Hsuan Chuang University, Taiwan \\ *Corresponding author: Pay-Ling Harn, Applied psychology Department, Hsuan Chuang University, Hsinchu City, Taiwan
}

Submission: 㘹February 12, 2018; Published: 無 February 28, 2018

\begin{abstract}
LEGO $®$ facilitative method is a new clinical intervention model, which utilizes the use of capacity construction to replace defect repair and promotes self-efficacy of the clients. LEGO is bricks include colorful, operational, visual, creative, and interesting that makes it a great tool for clients to promote' positive psychological reactions. This article introduces the development and framework of LEGO@SERIOUS PLAY@ and Six Bricks, and elaborates its clinical application of emotional regulation and cognitive reconstruction.
\end{abstract}

Keywords: Clinical intervention; LEGO®SERIOUS PLAY®; Six Bricks; Emotional regulation; Cognitive reconstruction

\section{Introduction}

Traditionally, talking therapy has been the primary model of psychological intervention. In recent years, the developments of expressive intervention modes of play therapy, art therapy, and sand play therapy have generated the clinical applications of multimedia. The modes above are aimed to help clients to explore deeper insights with media uncovering subconscious contents to emerge as part of the consciousness for individual awareness to arise. This article will introduce LEGO facilitative method as an innovative clinical intervention model that consists of a highly-structured process of expressing ideas and interpersonal communication by utilizing LEGO bricks. It emphasizes on unlocking knowledge and multiple thinking, rather than promoting the individual's subconscious awareness by utilizing media. LEGO® facilitative method is helpful for social connection, emotion conversion, cognitive development and action taking of the clients in clinic practice. The author will introduce strategies and categories of LEGO facilitative mode, and its application in clinical practice [1,2].

At present, there are two LEGO facilitative models used both domestically and internationally - LEGO® SERIOUS PLAY®(LSP) promoted by the Association of Master Trainers and Six Bricks and Play Box developed by LEGO Foundation. LEGO® SERIOUS PLAY® was initially utilized in developing business organization strategy, whereas Six Bricks and Play Box were used in learning and development for children. Currently, both LEGO facilitative methods have been extended to multiple applications in education, mental health, and family counseling. For example, Harn [3] established strength-centered LSP workshop to help survivors of domestic violence rebuild their interpersonal trust. Harn \& Hsiao [4] applied LSP and Six Bricks to developing a mode of workplace stress reduction. LSP is conducted by the facilitator who sets a series of goal-based questions. Participants respond to the questions with LEGO and sharing model stories. In the LSP model, participants must follow LEGO storytelling, rather than simply sharing personal stories, which facilitates depersonalization to increase the sense of security in the narrative process and to facilitate reframing personal experience. LSP brings emotional and behavioral changes through deliberative, innovative, and productive thinking [5]. Six Bricks model uses LEGO's nature of creation to stimulate people's unlimited creative thinking with simple bricks. Six Bricks consist of six $2 * 4$ dots DUPLO $囚 b r i c k s$ in red, orange, yellow, green, dark blue and light blue [1]. Six Bricks creates the positive effects of promoting language ability, problem solving, cooperation ability and emotional mediation. These two LEGO facilitative methods possess the benefits of the positive emotion and mind interaction [2]. Based on the Broaden and Build theory of positive emotion, the methods help to eliminate negative emotions, broaden thinking and build resources [6]. Based on the literature and practical experience, the author will explain the clinical application and benefits of LEGO $®$ facilitative methods.

\section{Emotional regulation}

Compared to traditional operational tools, LSP is a tool to create more fun [7]. "Playing" is a scheme individuals use to construct 
knowledge with the imagination, explore the world, and adapt themselves to society [8]. The positive emotions proposed by Fredrickson [6,9], shows "play" is the most important mechanism that leads to joy, interest, love, and other positive emotions. The author had used the method of LEGO ${ }^{\circledR}$ facilitative methods to clients who thought of suicide. The idea of suicide occurs when the clients become aware of the hopeless plight, accompanied by confusion and psychomotor retardation. In traditional interviews, the clients often face depression that hinders them from respond. LSP emphasizes telling model stories for depersonalization to increase a sense of security of the clients. In LSP for construction and narration, the author led the clients to start stories with the plight. The emotional transition produced by creativity and fun encouraged the clients to restructure their life stories and perceive his/her own abilities and resources. On the other hand, LEGO® bricks is the fixed media that could limit the expression of ideas. However, it sometimes can promote the conversion of thinking. There was once a client who tried to bind a mini figure with LSP linking components to present asphyxiation. However, the client tried and found it too difficult to finished it. Finally he changed to build a fort with bricks to present a self-care mental imagery.

The operation of Six Bricks model is similar to that of LSP. The difference lies in that Six Bricks can be either a single task or a series of tasks while LSP is usually the series of tasks. The author used group counseling to assist the clients with high self-disparagement and depression to convert emotion through group activities called "tricky tower" and "bridge". Colorful and bright DUPLO ${ }^{\circledR}$ bricks of Six Bricks bring joyful experience through vision to clients. Therefore, clients who participated in Six Bricks for the first time could quickly produce a positive psychological response visually and operationally, reducing their resistance to psychological intervention. The building tasks of Six Bricks are simple but challenging. Triggering the state of flow can increase clients engagement. In addition, this LEGO ${ }^{\circledR}$ task requires teamwork to enables depressed clients to develop substantive connections with others. With interesting team tasks, positive social interaction and personal values of the clients are promoted. Therefore, this model is quite helpful for those who are depressed and have the desires for interpersonal intervention in the author's practical observations.

\section{Cognitive restructuration}

Cognitive restructuration has two meanings. One is the regain of memory in clients with psychogenic amnesia, and the other is memory repair of patients with physiological memory degradation. Clinical cases of the former refer to the symptom of fragmental memory following the trauma or major stress events e.g. dissociative patients. In the past, some therapists used hypnosis and EMDR to retrieve memory images instead of the traditional talking therapy. It is the same that $\mathrm{LEGO} 囚$ facilitative models have the precondition of converting anxiety. The author once used LSP to help a client with dissociate depression to regain and integrate memories in the life. Through structured questions, the client was led to gradually build a scene of life memories. The narrative approach model was used to integrate the life experience. The client suffered emotional problems and memory loss since middle school. At first, the client was quite worried about whether he could regain the memory and hesitated to build LEGO structures. The author used the "handon thinking" principle of LSP to encourage the client to lead the narration of the model story. Through the images the memory was regained, followed by the narration of client's life story. In this way, the clients could integrate the life experience at different schooling stages. In addition, model as the focus of the story narration could keep the client move away from the perceived plights, which enables the client to view the personal issues with a larger scope. This is similar to the observation and distance intervention strategy of positive psychotherapy advocated by Peseschkian [10].

Conducting LSP requires meticulous thinking. The clients who have psychogenic amnesia will occasionally lead to frustration with failure to regain large amounts of memory. In this situation, facilitators should give clients adequate encouragement, or considerate using more flexible methods such as Six Bricks or DUPLO ${ }^{\circledR}$ bricks. In addition, group counseling models have been used traditionally to enhance or maintain their memory function by using "imitation" and "copy" activities to the patients who have physiological memory degradation with Schizophrenia or with Parkinson's disease. Perceptual skill and memory development activities in Six Bricks such as "Pattern sounds", "build your memory" and "copy model" are all quite suitable for the memory repair and maintenance for these patients. $\mathrm{LEGO}{ }^{\circledR}$ bricks have the sensory experiences in vision, tactile sensation and hearing, which not only activate brain functioning but also promote limb functions [11].

\section{Conclusion}

LEGO $®$ SERIOUS PLAY $®$ and Six Bricks originate respectively from business and education areas. In recent years, the use of LEGO ${ }^{\circledR}$ facilitative methods in practical cases of mental health and empirical research is in development. Both methods lead to the effect of positive psychological mechanism to promote emotional regulation and cognitive restructuration of the clients. The application of this model in clinical practice will have a high developmental potential different from the defects of traditional medical model because this model creates a positive psychological healing environment and promotes the capacity building and resource rebuilding of clients.

\section{References}

1. https://www.changemakers.com/play2learn/entries/back-basics-6bricks

2. Kristiansen P, Rasmussen R (2014) Building a better business using the serious play method. In: Kristiansen P, Rasmussen R (Eds.), Building a better business using the serious play method. John Wiley \& Sons, New York, USA.

3. Harn PL (2017) A preliminary study of the empowerment effects of strength-based LEGO®

SERIOUS PLAY ${ }^{\circledR}$ on two taiwanese adult survivors by earlier domestic violence. Psychological Studies, 62(2): 142-151.

4. Harn PL, Hsiao CC (2018) A preliminary study on LEGOß-Based workplace stress reduction with six bricks and LEGO®SERIOUS PLAY® 
in Taiwan. World Journal of Research and Review 6(1): 64-67.

5. Rasmussen R (2017) Facilitation clinic of LSP. Paper present at 2017 Asia community conference for certified facilitators of LEGO® SERIOUS PLAY®, Tokyo, Japan.

6. Fredrickson BL (2009) Positivity. In: Fredrickson BL (Ed.), Positivity. Three rivers press, New York, USA.

7. Schulz KP, Gelthner S, Woelfe C, Krzywinskl J (2015) Toolkit-based modeling and serious play as means to foster creativity in innovation process. Creativity and innovation management 24(2): 323-340.
8. Nahamura J, Csikszentimihalyi M (2014) The concept of flow. In: Csikszentimihalyi M (Ed.), Flow and foundations of positive psychology. Springer, New York, USA, pp. 227-263.

9. Fredrickson BL (2001) The role of positive emotions in positive psychology: The broaden and build theory of positive emotions. American Psychologist 56(3): 218-226.

10. Peseschkian N (1987) Positive psychotherapy: Theory and practice of a new method. In: Peseschkian N (Ed.), Springer, New York, USA.

11. LEGO® Foundation (2016) Back to basic bricks with six bricks. CFE, Johannesburg, SA.

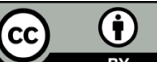

Creative Commons Attribution 4.0 International License

For possible submissions Click Here

\section{Submit Article}

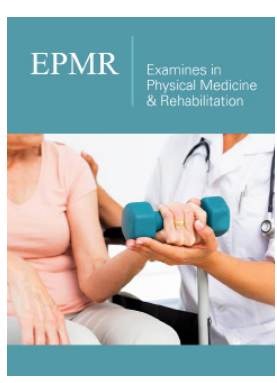

Examines in Physical Medicine and Rehabilitation: Open Access

\section{Benefits of Publishing with us}

- High-level peer review and editorial services

- Freely accessible online immediately upon publication

- Authors retain the copyright to their work

- Licensing it under a Creative Commons license

- Visibility through different online platforms 